\title{
Calming the Monkey Mind
}

\author{
Kendra Eliuk ${ }^{1} \&$ David Chorney ${ }^{1}$ \\ ${ }^{1}$ Department of Secondary Education, University of Alberta, Canada \\ Correspondence: Kendra Eliuk and David Chorney, Department of Secondary Education, Office 448 Education \\ South, 341 Education South, University of Alberta, Edmonton, AB, T6G 2G5, Canada. E-mail: kjeliuk@ualberta.ca \\ or dchorney@ualberta.ca
}

Received: January 24, 2017

Accepted: February 7, 2017

Online Published: February 23, 2017

doi:10.5430/ijhe.v6n2p1

URL: https://doi.org/10.5430/ijhe.v6n2p1

\begin{abstract}
Many of today's students are experiencing higher levels of stress and anxiety in school. The need for competitive grades, the desire to be seen as perfect in a digital society, and parental pressures are only some of the reasons that students are experiencing more stress. This increased stress has lead to an overworked mind for many youth, dubbed a 'monkey mind' in which they cannot calm or control their thoughts. This article examines possible causes of a 'monkey mind' and explores the beginning of how students may learn to calm and control their 'monkey mind' through mindfulness training. Several examples of mindfulness training in different classroom scenarios are introduced, and the relationships between our connections to everything around us are explored. The article serves to provide a starting point for educators who may feel at a loss for how to help their students manage their stress and anxiety levels.
\end{abstract}

Keywords: Adolescent, Stress, Anxiety, Mindfulness, School

\section{Introduction}

Wakeup, teach, coach, study, plan, and repeat. These words describe my typical day, and similarly the days of many of my colleagues. I often have trouble falling asleep, my mind racing with thoughts of future lessons, past conversations and ideas for coaching. Students are shuttled from activity to activity by their parents, so that their future University admission packages can be complete with all boxes checked when the time comes to apply for post-secondary admission. There is a constant push from many sides for students and teachers to be smarter, faster, overall 'better' and to do this all before anyone else does. Where is this rushed lifestyle leaving us? What goals are we hoping to accomplish - the ability to be first on social media?, or the satisfaction of personal achievements? And what are we missing out on as we constantly push and rush forward, without taking the time to appreciate where we are and where we have been?

Bai (2015) speaks of the 'monkey-mind', where we are constantly running ideas and thoughts through our brains. She notes that "[w]e are so deeply conditioned, as it were, to run on the monkey mind program, that it is very difficult for us to switch off the program" (2015, p. 144), which is indeed true of many people. Many of today's children are also developing a 'monkey-mind' as evidenced by our own lived experience with students who are already, in grades eight and nine, immensely concerned about their school grades and future University application packages, more so than students even 10-20 years ago. Not only does the 'monkey-mind' create unneeded stress and anxiety, but it halts our connection to people and things around us, an idea that is very important to many curriculum theorists (Bai \& Cohen, 2014; Jardine, 1999; Miller, 2005; Sumara, 1999). There are connections within ourselves, and to all things around us, from a mind/body connection, to those with other people, to connections with the environment and the world around us. Instead, we see ourselves as separate from our world, rather than being a part of it (Bai \& Scutt, 2009), leading to inflation of our ego as we put our needs and ourselves first. This inflation of ego continues the cycle of focusing on our goals and trying to better ourselves, but often comes at a cost to others. Current thinking for some students is that their best is not good enough if someone else is achieving more. So we continue to push for more, never happy in what we have, never fully present in the moment we are experiencing. We must instead "become aware of [ourselves] in relation to each other and [the] world" (Sumara, 1999, p. 304).

Jardine notes that even in education we are "so caught up in this senseless roar and rush" (1999, p. 263) as parents, students and administrators demand better results, faster learning and higher scores. We no longer have the ability or 
time to teach a curriculum of caring, instead focusing on "learning for skill and financial success" (Moore, 2005, p. 13) which are "relevant to the ego, but they obscure the needs of the soul" (p. 13). How can we teach students to nourish the needs of their soul? What does the soul need? Many educators feel ill-prepared to teach students about basic Health issues due to a lack of training during their teacher preparation programs (Basch, 2011; Lechtenberger, et al., 2008; Manion et al., 2012; Walter et al., 2011), much less ways to deal with anxiety and create connections to 'nourish the soul'. In fact, undergraduate teacher training courses which focus on mindfulness, creating connections and a curriculum of caring, are currently rare to see in Canada. This paper will look at how educators can begin to teach students about a curriculum of caring by working to calm their 'monkey-mind' through mindfulness and breathing techniques. Through the literature review undertaken for this article, we will show the importance of teaching mindfulness to educators and students, how these techniques can be used to create connections between our mind and body, as well as with those around us, and how they will help students experience their present more fully.

\section{Connectedness}

As noted above, our society has become a fast paced environment where we are never content with our current situation, always striving for more. The practice of Buddhism believes that there are three poisons that corrupt our heart-mind: desire, hatred, and ignorance (Park \& Song, 2005). If we can rid ourselves of these three poisons, we return to our original state of harmony, our basic goodness. Instead, we continue to feed our 'hungry ghosts' (Bai, 2012), our ego and needs, though we are never satiated with what we have. As teachers, we need to focus on our "integrity and dignity, wisdom and compassion" (Bai, 2012, p. 320) to create a curriculum of caring. Focusing on our connection to each other will help with this. Our lack of connection can be seen through the current levels of cyber-bullying occurring online. Many people feel comfortable typing rude or disrespectful comments to a screen, but would never consider saying the same thing directly to another person. Even the small connection of being face to face, seeing the reaction is enough to make people reconsider their words. As we begin to realize and develop our connections to others, we "naturally [practice] humility, compassion, care and generosity" (Bai, 2008, p. 113).

Miller (2005) describes three basic principles of holistic education: connectedness, inclusion, and balance. Connectedness refers to facilitating connections throughout our educational experiences. Inclusion seeks to engage all students, and teach them in a manner that they can understand. Balance recognizes the complementary forces in nature, and encourages educators to provide for both forces. The example of such forces given by Miller (2005) describes our push for rational thinking and individual competition in a classroom, instead of looking to teach attitudes of intuition and cooperation. Our current system is set up to encourage this competition, for entry into specialized programs, University degrees, and jobs. Awards are given to the top students at the end of each year. What would our classroom look like if we focused instead on the achievements of every student? The lack of connection with their school that many students experience, coupled with a system that caters primarily to the student who can learn through standard teaching methods and an environment of competition, has created highly stressful situations for many students. Even those who are successful in this environment continue to feel anxiety in trying to stay at the top. How can mindful practice reduce this anxiety and help create a connected, inclusive and balanced classroom? Will these practices calm the minds of our students, teaching them to "take care and consideration and [pay] deep attention to what [they] are doing" (Jardine, 1999, p. 272)?

\section{Mindful Practice}

While mindful practice is often considered in conjunction with Eastern practices, it has recently moved into our mainstream classrooms. It is often used in place of meditation, though it encompasses more than just breathing techniques. Mindfulness involves "consciously bringing our awareness to the present moment - to the here-and-now experience" (Gardner \& Grose, 2015, p. 35). It does not involve suppression of feelings or emotions, but instead, a recognition and acceptance of these thoughts non-judgmentally (Gardner \& Grose, 2015). It is "being in the moment; focusing upon the action - even the action of holding stillness - and finding a deep appreciation for whatever it is" (Francis \& Lu, 2009, p. 24). Bai describes a 'stop' in the practice of mindfulness, "where the automaticity of thought comes to a halt and gives away to an embodied awareness" (2015, P. 140). This is how we can become more mindful of our practice, our thoughts and emotions, essentially calming our 'monkey-mind' through mindful practice.

Mindful practice may involve relaxation activities such as meditation, rhythmic activities such as swimming, watching the ocean (Bellin, 2015; Bigdeli \& Bai, 2009; Forbes, 2005), or spending time engaged in art (Shaprio, Lyons, Miller, Butler, Vieten \& Zelazo, 2015). Bellin (2015) cites Brach in offering a basic mindful practice described by the acronym RAIN. In becoming more aware of the current feeling or emotion, the practitioner is encouraged to 'Recognize' the presence of the feeling or emotion and label it if necessary. Next, the practitioner is asked to 'Allow' the feeling or emotion to be fully experienced as it occurs. 'Investigate' allows the practitioner to 
fully explore the feeling or emotion with curiosity and kindness, understanding how it changes and moves from moment to moment. Finally, the practitioner 'Nonidentifies' the feeling or emotion, releasing it again and again until the feeling or emotion has lost its momentary hold. Bigdeli and Bai (2009) offer a similar thought in that mindfulness allows a person to identify and understand their anxiety better. In identifying situations that cause anxiety and the reaction to these situations, mindful practice, as noted by Bellin (2015), allows a person to self-reflect on his/her response to the anxiety, offering the opportunity to manage his/her response to the situation. If we are mindfully aware of the situation, we can react and respond to it in a positive manner. Bigdeli and Bai (2009) are also quick to point out that anxiety can be a positive and healthy emotion. It is only when stress and anxiety are the constant driving force behind our actions that it becomes a negative and destructive force (Bigdeli \& Bai, 2009; Moore, 2005).

\section{Teaching Mindfulness}

As evidenced through local Comprehensive School Health group discussions, mindfulness practice is becoming mainstream in many classrooms within my school district, often helping students in younger grades reduce anxiety levels before a big test, lessen incidences on bullying, or to help calm a hyperactive class (Leland, 2015). In looking at methods of mindful breathing or meditation, there are numerous websites and apps that can be easily used in a classroom or at home. One example; www.stopbreaththink.org offers guided breathing audio clips, ranging from three minutes to 20 minutes, which encourage the practice of mindful thought in the present. Teachers may use this program as part of their morning routine, preparing students to learn for the day, or at a point in their class where students need to calm their anxieties or hyperactivity. Allowing three to five minutes of mindful practice before an exam may help calm the anxieties of some students, allowing them to clear their mind before beginning the test. With the StopBreathThink app, students are asked to sit, close their eyes and focus on their breathing. They feel the chair under them, the ground under their feet, all the while, guided through relaxed breathing. Students emerge from the meditative process with a calmer mind and a connection to the present, more ready and able to learn. Shaprio et al. (2015) have compiled a comprehensive list of mindfulness programs, such as iRest for Kids, MindUp, Learning to Breath, Wellness Works in Schools and Little Flower Yoga, along with brief descriptions about the program, their implementation, and the goals of the program, that may be further explored. Younger children also benefit highly from the use of story to help practice mindfulness so that they may calm their anxiety. Anxiety, which is often caused by a lack of connection, a feeling of inadequacy, or a loss of control, (Haubrich, 2016) is the first mental health disorder to appear in young children (Neil \& Christensen, 2009, p. 209; Haubrich, 2016). As young children do not yet have the mental capacity for reasoning, they are often unable to understand and cope with their anxiety when it strikes. The use of story helps children to practice mindfulness as they are engaged in the story in the present. Rather than focusing on their emotions, they are able to clearly and logically work through the problems of the character, offering them insight into their own anxiety at a later date. The practice of self-regulation through this approach allows children the opportunity to work through new challenges or problems in calm and safe manner (Shapiro et al., 2015).

Articles are now beginning to appear more frequently on the use of mindful practice in the classroom, though teachers must remember that as "mindfulness is based upon now, mindful teachers stress the process as much as the product" (Francis \& Lu, 2009, p. 24). In describing mindfulness practice in a physical education setting, Francis and $\mathrm{Lu}$ (2009) remind us to focus on simplicity, oneness, and interdependency when introducing mindful practice. Simplicity focuses on the idea that less is more. Trying to achieve more to impress others will not help in the practice of mindfulness. Instead, students should allow a phenomenon to just be. It should not be judged as good or bad, but just as 'is'. This is a difficult concept in a competitive sport driven class, yet teachers should strive to understand all movement as beautiful, just for being movement itself, a very aesthetic notion. Oneness recognizes that everything in the universe is connected and inseparable. We must maintain a balance with our connections to ensure that all involved stay healthy. In a physical education classroom, this involves paying attention to our bodies and our thoughts to ensure that we do not cause them harm in trying to achieve something more. Here, a positive attitude towards all physical activity is promoted, instead of focusing on specific skills, or non-inclusion of students through competitive games. Interdependency recognizes that all of our actions will have some effect on those around us. In a physical education setting, students should be encouraged to work cooperatively and collaboratively rather than focusing on competition between individuals. Thinking back to Miller's (2005) idea of creating a classroom that focuses on connections, inclusion and balance, the ideas put forth here by Francis and Lu (2009) echo those of Miller. Oneness focuses on including students who may not feel welcomed in a physical education setting, while interdependency helps to create connections through balance. Simplicity here helps to stem the feelings of competitiveness between classmates, and also helps to slow the 'monkey-mind' in stressing the importance of 
enjoying the activity simply as it is. Instead of pushing for a competitive, skill-based approach to Physical Education, students should be encouraged to participate for the sheer joy of movement and being physically active, as exemplified in the Alberta Physical Education curriculum where students are encouraged to 'Do it Daily...For Life!' (Alberta Education, 2000). They should try to remain in the moment of their activity, focusing on the "joy of a movement sensation" (Francis \& Lu, 2009, p. 24), or on the feeling of their heart beating faster at the end of a class. Another simple example is to save instruction until after students have completed a warm-up and stretch (Francis and $\mathrm{Lu}, 2009)$. Many teachers will give instruction during a warm-up stretch, not allowing students the time to listen to their bodies as they stretch, and enjoy the feeling of sinking further into their stretch. While these examples are situated in a physical education setting, these three ideas of 'oneness', 'interdependency' and 'simplicity' can be easily applied to any classroom scenario.

Barry (2014) also offers insight into mindfulness practices through art that may be useful to secondary teachers. Her classes are focused on studying the movement of information between people through the use of images rather than words and dialogue. While her classes focused heavily on drawing, being 'good' at drawing was not a requirement. Instead, students are encouraged to be present in the experience of drawing, and to allow the drawing to come into being itself. Often, students are asked to draw spirals as a way of focusing their mind on the task at hand. This method is similar to the focusing techniques used in meditative breathing to help calm and centre the mind on a specific task, allowing the student to be present in the moment as they focus on drawing the spiral lines as close together as possible without touching. Barry describes the drawing of spirals as "an exercise in both relaxation and concentration" (2014, p. 76), allowing students to focus on their present task at hand.

Barry (2014) also makes note of how her drawings come into being. She claims that she never sets out to draw her characters; they just "seem to show up" $(2014$, p. 144). She also comments on the passing of time, and when she begins to draw and then nears completion, she can barely remember having even started the drawing. Her drawings take on a life of their own, and Barry (2014) encourages her students to accept their drawings as they are. There is no notion of good drawings or bad drawings. They just are. Her students are immersed mindfully on the task at hand, and they must be willing to accept what appears, not questioning, not judging, only accepting.

\section{Mindful Practice and our Connections to Others}

How then does this practice calm the 'monkey-mind' and create connections to others. As shown previously, mindful breathing practices helps slow the breathing of the individual. As he/she is asked to recognize feelings and thoughts, experience them and release them away from themselves, mindfulness helps to calm the racing thought of the 'monkey-mind'. Students are able to identify their thoughts, acknowledge them, and release them so that they no longer weigh heavily on their minds. This awareness of emotion and thoughts also helps to stem feelings of anxiety. Students can focus calmly on their stressors and clearly reflect on how they should react to the situation. This practice allows students to better manage their anxiety around testing situations or due to stressors outside of their school lives, thus giving them the skills to instead focus on their learning rather than their anxieties. As previously noted, one major cause of stress is a lack of connection (Bigdeli \& Bai, 2009; Haubrich, 2016). Children feel isolated because they do not know how to handle a situation and believe they have nobody to help them through it. Calm and mindful practice not only allows them to logically work through a problem, but they are also better able to relate their current situation back to previous situations they may have already experienced, offering solutions that are not apparent during a worked up state of crisis.

Students are also able to connect with others and their environment on a deeper level as they become more deeply connected with the experience. Mindful practice has been shown to help build interpersonal skills (Broderick \& Frank, 2014), helping students develop stronger connections to those around them, both peers and teachers.

Bai and Scutt note that mindfulness "connects, integrates, and transfuses everything" (2009, p. 101), and our practice of mindfulness opens our hearts to wonder and gratitude. As we begin to experience this wonder more mindfully, in the present, we are now stopping the "senseless roar and rush" (Jardine, 2009, p. 263) and beginning to fully appreciate things around us. Once we can understand that "any object, even the most trivial of things, is in the center of this interdependency, with all things ordered around it" (Jardine, 2009, p. 265), it becomes much harder to react in a negative manner towards it. Barry's (2014) example of allowing her characters to just be, dispels the need for 'good' versus 'bad', another thought which has been postulated by Bai (2012). In accepting things as they are, we have a better chance of understanding them. Thus begins our connection to everything and everyone around us. 


\section{Barriers to Mindful Practice}

One of the biggest barriers to the inclusion of mindfulness practice in schools is a lack of teacher training in the area of Health Education (Basch, 2011; Lechtenberger, et al., 2008; Manion et al., 2012; Walter et al., 2011). Many teachers are not required to take a Health Education course during their teacher training, often leading to a lack of comfort in their classroom with the subject. As an educator must have "commitment and familiarity with mindfulness skills" (Mendelson, Dariotis, Feagans Gould, Smith, Smith, Gonzalez \& Greenberg, 2013, p. 280) to ensure success of a mindfulness based program, it is imperative that all educators receive some form of pre-service teacher training in the area of Health Education, mental well-being and mindfulness. This training also ties in with allowing students to understand and form connections with themselves, those around them and their surrounding world. Salzberg (1995) speaks of a loving-kindness connection, in which focused attention, or mindfulness practice is used to create positive emotion towards one's self and others around them. Where should these practices be taught? Should a required Health Education class be offered for every pre-service teacher? Perhaps at least one lecture during an 'Introduction to Educational Psychology' course could focus on these ideas. As an added benefit, teachers themselves would be learning the mindful practice skills they may need to reduce their own stress levels and thus better self-regulate emotions in front of a group of students during a stressful day on the job (Roeser, Skinner, Beers \& Jennings, 2012). Mendelson et al. (2013) note that several programs of this nature have begun to emerge in recent years, such as the 'Cultivating Awareness and Resilience in Education' (CARE) program, 'Stress Management and Relaxation Techniques in Education' and 'Comprehensive Approach to Learning Mindfulness', but they are aimed at current teachers choosing to participate in these programs. Through the promotion of Health Education and mindful practice in post-secondary teacher training programs, we will begin to see a trickle down effect to more students, eventually teaching them the skills to calm their anxious 'monkey-mind' and begin to form connections to themselves and to those around them.

Another barrier to mindfulness training in school is a lack of administrative support. The need for time, space and support are vital to the success of these programs, and school administrators are often focused solely on the measurable indicators of student achievement rates in the areas of literacy and numeracy. However, "[h]ealthier students are better learners" (Basch, 2011, p. 651), and programs rooted in mindfulness training can help students be healthier, leading to higher levels of learning and achievement. Smith-Carrier, Koffler, Mishna, Daciuk and Zeger (2015) found that mindfulness training provided by the Mindfulness Ambassador Council (MAC) in Toronto aided students in reducing their stress and anxiety, improved their executive functions, helped them to regulate their emotions, build interpersonal skills and promoted their inner well being. Not only did the MAC aid students in calming their 'monkey-mind', students built connections with those around them. This reduction of stress and anxiety, and the promotion of positive relationships with those around them can lead to a stronger learning environment for students, and to a reduction in behavioural issues in the school environment, allowing for higher levels of learning for all students (Beauchemin, Hutchins \& Patterson, 2008; Franco, Mañas, Cangas \& Gallego, 2010; Smith-Carrier et al., 2015).

\section{Conclusion}

As our society becomes ever more competitive and we continue to race forward as fast as we can, we need to remember to take time to enjoy our present experiences as they are. Our personal 'monkey-mind' and our desire to feed our hungry ghosts do little to move us forward. Instead, we are left feeling tired, anxious and stressed as our overall health deteriorates. As well, our world is plunged even more into a hateful rhetoric as we fail to make connections with people, which are vital in order to be able to understand one another. Instead, our focus is on ourselves, on feeding our own ego so that we may come out on top. The practice of mindfulness will allow us to slow our minds and focus on enjoying the present. As well, through our thoughtful exploration of these moments, we are able to connect more intimately with the people and environment around us, strengthening our personal well-being. Teaching mindful practice in our schools will instill this calming effect on students' minds, teaching them the skills required to understand and manage their anxiety and stress. This reduction in anxiety and stress allows students to focus on their present, enabling them to be better learners who are more focused and engaged in their learning. As well, this practice will reinforce their connections to others, improving their inter-personal relationships with other students and their teachers within their school. Through mindfulness practices, students will be better able to understand their relationships with others and how their actions may have an impact on others. This will lead to a stronger connection between students and their school community, and also to a better understanding of our similarities and our differences, helping everyone to create a more positive global community. 


\section{References}

Alberta Education (2000). Physical Education Program of Studies. Retrieved from: https://education.alberta.ca/media/160191/phys2000.pdf

Bai, H. (2008). Out beyond the ideas of wrongdoing and rightdoing... Complicity. An International Journal of Complexity and Education 5(1), 109-114. Retrieved from http://eds.a.ebscohost.com/eds/pdfviewer/pdfviewer?vid=18\&sid=1249b5a3-3a7b-4a23-aa9c-82732de7bd13\% 4 0sessionmgr $4005 \&$ hid $=4113$

Bai, H. (2012). Reclaiming our moral agency through healing: A call to moral, social, environmental activists. Journal of Moral Education, 41(3), 311-327. https://doi.org/10.1080/03057240.2012.691628

Bai, H. (2015). Peace with the earth: Animism and contemplative ways. Cultural Studies of Science Education, 10(1), 135-147. https://doi.org/10.1007/s11422-013-9501

Bai, H. \& Cohen, A. (2014). Zen and the art of storytelling. Studies in Philosophy and Education, 33(6), 597-608. https://doi.org/10.1007/s11217-014-9413-8

Bai, H., \& Scutt, G. (2009). Touching the earth with the heart of enlightened mind: The Buddhist practice of mindfulness for environmental education. Canadian Journal of Environmental Education, 14(1), 92-106. Retrieved

from http://eds.a.ebscohost.com/eds/pdfviewer/pdfviewer?vid=20\&sid=1249b5a3-3a7b-4a23-aa9c-82732de7bd13\%4 0sessionmgr $4005 \&$ hid $=4113$

Barry, L. (2014). Syllabus: Notes from an accidental professor. Canada: Drawn \& Quarterly.

Basch, C. E. (2011). Healthier students are better learners: High-quality, strategically planned, and effectively coordinated school health programs must be a fundamental mission of schools to help close the achievement gap. Journal of School Health, 81(10), 650-662. https://doi.org/10.1111/j.1746-1561.2011.00640.x

Beauchemin, J., Hutchins, T. L., \& Patterson, F. (2008). Mindfulness meditation may lessen anxiety, promote social skills, and improve academic performance among adolescents with learning disabilities. Complimentary Health Practice Review, 13(1), 34-45. https://doi.org/10.1177/1533210107311624

Bellin, Z. J. (2015). The meaning connection between mindfulness and happiness. Journal of Humanistic Counseling 54, 221-235. https://doi.org/10.1002/johc.12013

Bigdeli, S., and Bai, H. (2009). The triunal model of anxiety and its application to anxiety reduction in learning and teaching environments. TESL Canada Journal, 27(1), 103-114. https://doi.org/10.18806/tesl.v27i1.1029

Broderick, P. C., \& Frank, J. L. (2014). Learning to BREATHE: An intervention to foster mindfulness in adolescents. New Directions for Youth Development, 142, 35-46. https://doi.org/10.1002/yd.20095

Forbes, D. (2005). In da zone: Meditation, masculinity and a meaningful life. In J. P. Miller, S. Karsten, D. Denton, D. Orr, \& I. C. Kates (Eds.), Holistic Learning and spirituality in education: Breaking new ground (1-6). Albany: State University of New York Press. Retrieved from: http://eds.b.ebscohost.com/eds/detail/detail?nobk=y\&vid=6\&sid=ff4bd527-6a8b-4ef4-a8b4-8d926055886e@se ssionmgr110\&hid=126\&bdata=JnNpdGU9ZWRzLWxpdmUmc2NvcGU9c210ZQ==\#AN=145004\&db=e000xn a

Francis, N., \& Lu, C. (2009). The conceptual framework of the Eastern approach in physical education: Ancient wisdom for modern times. ACHPER Healthy Lifestyles Journal, 56(2), 23-27. Retrieved from http://eds.a.ebscohost.com.login.ezproxy.library.ualberta.ca/eds/pdfviewer/pdfviewer?vid=3\&sid=70a441cc-df5 b-4edd-9a12-dce43119ffc7@ sessionmgr4001\&hid=4211\&preview=false

Franco, C., Mañas, I., Cangas, A. J., \& Gallego, J. (2010). The applications of mindfulness with students of secondary school: Results on the academic performance, self-concept and anxiety. Knowledge Management, Information Systems, E-learning, and Sustainability Research 111. https://doi.org/10.1007/978-3-642-16318-0_10

Gardner, P., \& Grose, J. (2015). Mindfulness in the academy - transforming our work and ourselves 'one moment at a time'. Collected Essays on Learning and Teaching, 8, 35-46. Retrieved from http://files.eric.ed.gov/fulltext/EJ1069707.pdf

Haubrich, A. (2016). Hurried and worried: Understanding elementary anxiety. Conference session from the Greater Edmonton Teachers Convention Association. 
Jardine, D. (1999). A bell ringing in the empty sky. In W. F. Pinar (Ed.), Contemporary curriculum discourses: Twenty years of JCT (262-277). New York: Peter Lang.

Lechtenberger, D., Mullins, F. E., and Greenwood, D. (2008). Achieving the promise: The significant role of schools in transforming children's mental health in America. Teaching Exceptional Children, 40(4), 56-64. https://doi.org/10.1177/004005990804000407

Leland, M. (2015). Mindfulness and student success. Journal of Adult Education, 44(1), 19-24. Retrieved from: http://search.proquest.com.login.ezproxy.library.ualberta.ca/cv_734690/docview/1709527310/fulltextPDF/741 D5016D364492FPQ/12? accountid=14474

Manion, I., Short, K. H., \& Ferguson, B. (2012). A snapshot of school-based mental health and substance abuse in Canada: Where we are and where it leads us. Canadian Journal of School Psychology, 28(1), 119-135. https://doi.org/10.1177/0829573512468847

Mendelson, T., Dariotis, J. K., Feagans Gould, L. Smith, A. S. R., Smith, A. A., Gonzales, A. A., \& Greenberg, M. T. (2013). Implementing mindfulness and yoga in urban schools: A community-academic partnership. Journal of Children's Services, 8(4), 276-291. https://doi.org/10.1108/JCS-07-2013-0024

Miller, J. P. (2005). Holistic learning. In J. P. Miller, S. Karsten, D. Denton, D. Orr, \& I. C. Kates (Eds.), Holistic Learning and spirituality in education: Breaking new ground (1-6). Albany: State University of New York Press. Retrieved from: http://eds.b.ebscohost.com/eds/detail/detail?nobk=y\&vid=6\&sid=ff4bd527-6a8b-4ef4-a8b4-8d926055886e@ @e ssionmgr110\&hid=126\&bdata=JnNpdGU9ZWRzLWxpdmUmc2NvcGU9c210ZQ==\#AN=145004\&db=e000xn a

Moore, T. (2005). Educating for the soul. In J. P. Miller, S. Karsten, D. Denton, D. Orr, \& I. C. Kates (Eds.), Holistic Learning and spirituality in education: Breaking new ground (9-15). Albany: State University of New York Press. $\quad$ Retrieved from http://eds.b.ebscohost.com/eds/detail/detail?nobk=y\&vid=6\&sid=ff4bd527-6a8b-4ef4-a8b4-8d926055886e@ se ssionmgr110\&hid=126\&bdata=JnNpdGU9ZWRzLWxpdmUmc2NvcGU9c210ZQ==\#AN=145004\&db=e000xn a

Neil, A. L., \& Christensen, H. (2009). Efficacy and effectiveness of school-based prevention and early intervention programs for anxiety. Clinical Psychology Review, 29, 208-215. https://doi.org/10.1016/j.cpr.2009.01.002

Park, Y., \& Song, M. (2005). Won Hyo's One Heart-Mind and Meditation on One Heart-Mind as Part of Holistic Education. In J. P. Miller, S. Karsten, D. Denton, D. Orr, \& I. C. Kates (Eds.), Holistic Learning and spirituality in education: Breaking new ground (109-116). Albany: State University of New York Press. Retrieved from http://eds.b.ebscohost.com/eds/detail/detail?nobk=y\&vid=6\&sid=ff4bd527-6a8b-4ef4-a8b4-8d926055886e@ se ssionmgr110\&hid=126\&bdata=JnNpdGU9ZWRzLWxpdmUmc2NvcGU9c210ZQ==\#AN=145004\&db=e000xn a

Roeser, R. W., Skinner, E., Beers, J., \& Jennings, P. A. (2012). Mindfulness training and teachers' professional development: An emerging area of research and practice. Child Development Perspectives, 6(2), 167-173. https://doi.org/10.1111/j.1750-8606.2012.00238.x

Salzberg, S. (1995). Lovingkindness: The revolutionary art of happiness. Boston: Shambhala Press.

Shaprio, S. L., Lyons, K. E., Miller, R. C., Butler, B., Vieten, C. \& Zelazo, P. D. (2015). Contemplation in the classroom: A new direction for improving childhood education. Educational Psychology Review, 27, 1-30. https://doi.org/10.1007/s10648-014-9265-3

Smith-Carrier, T., Koffler, T., Mishna, F., Wallwork, A., Daciuk, J., \& Zeger, J. (2015). Putting your mind at ease: Findings from the Mindfulness Ambassador Council programme in Toronto area schools. Journal of Children's Services, 10(4), 376-392. https://doi.org/10.1108/JCS-10-2014-0046

Sumara, D. J. (1999). Of seagulls and glass roses: Teachers' relationships with literary texts as transformational space. In W. F. Pinar (Ed.), Contemporary curriculum discourses: Twenty years of JCT (289-311). New York: Peter Lang.

Walter, H. J., Gouze, K., Cicchetti, C., Arend, R., Mehta, T., Schmidt, J., \& Skvarla, M. (2011). A pilot demonstration of comprehensive mental health services in inner-city public schools. Journal of School Health, 81, 185-193. https://doi.org/10.1111/j.1746-1561.2010.00578.x 